\author{
Crossing the Border: International Journal of Interdisciplinary Studies \\ Volume 5; Number 2; 15 July 2017 \\ ISSN 2350-8752 (Print); ISSN 2350-8922 (Online)
}

\title{
HUMANITY IN BP KOIRALA'S SUMNIMA
}

Min Nepali (Nepal)

\begin{abstract}
BP Koirala in Sumnima believes in the idea that the essence of any civilization is the quest for a common humanity and not the zeal for cultural and religious orthodoxy. It empowers the need of cultural synthesis, for whatever is good, beautiful and useful must be learnt and be assimilated for the benefit of larger humanity. The novelist wishes for the evolution of humanist culture to be enriched by the contribution of all religions. Sumnima, the protagonist of the novel, believes in cultural and religious orthodoxy and rejects other religions and cultures. In addition, she realizes her mistake and stretches her arms towards humanism. She also realizes that one should not be confined in the narrow sectaries of caste, religion and cultural orthodoxy which are a mere social practice. These polarities only divide human beings and prevent to achieve unlimited possibilities of human life. Thus, this paper aims to suggest that humans should make their effort for an ultimate harmony between humans and society.
\end{abstract}

KEYWORDS: Humanity; culture; orthodoxy; caste; cross border

\section{INTRODUCTION}

The present study focuses on Koirala's Sumnima, a story of conflict and reconciliation between Aryan and Kiranti culture. The novel runs through misunderstanding to understanding, orthodoxy to liberalism and fragmentation to unification. The protagonist set her journey from cultural and religious rigidity to the wider world of humanism. The gradual development in the novel portrays the development of the protagonist's enlightenment process. The novel is in fact a journey from a narrow and strict cultural and religious orthodoxy or any sectarianism into all embarrassing humanism that is universal in its nature and humanistic in its approach.

Koirala's novel presents the characters of two different castes, following two different cultures and traditions. The novel begins with the meeting of Somdatta, the son of Aryan priest- Suryadatta and Sumnima, the daughter of Kirant Bizuwa:

The damsel innocently replied, 'I am Sumnima, a Kirat daughter. By the way, who are you yourself hey weak-bodied boy?'

Somdatta said, 'I am Somdatta, son of Suryadatta, a Brahmin belonging to the Aryan stock.' (Koirala, 2005, p. 7)

They become friends very soon and begin to meet almost every day at the Koshi bank. To maintain the spiritual notion, Somdatta keeps himself busy in ritual and meditations, surrenders to complete asceticism, and retains compulsive discipline. $\mathrm{He}$ 


\section{Crossing the Border: International Journal of Interdisciplinary Studies}

disapproves the attraction of physical desire and dreams. For him, the world of senses, the body, passions, and desires of men are foes. Unlike him, Sumnima has faith in worldliness, physicality and objective reality. As they represent different cultures and beliefs, they put their ideas accordingly. Sometimes they fall on a hot debate.

As directed by his father, Somdatta goes on pilgrimage and performs rigorous yogas to attend spiritual refinement. After his return, he readily embraces the ascetic way of life and gets married to a woman Puloma as desired by his father. He gets married not to fulfill his physical passion rather to continue his posterity as demanded by his dharma. Due to their old age, Somdatta's parents desire to abandon the worldly attachment and so they handover the household affair to Somdatta and Puloma. Somdatta, according to Vedic arrangement, performs yagnyas for his wife's pregnancy and the birth of a son. But all his rituals performed for childbirth fail and both Somdatta and Puloma get tired of these rituals. As a result, Somdatta leaves home fed up with the monotonous rituals of intercourse and goes towards the Kirant village.

Looking for the house of Bizuwa, the father of Sumnima, Somdatta wanders around the village and meets Sumnima on the way. At first, none of them recognizes each other. Later Sumnima recognizes Somdatta with some sign on his body and she takes him to her home. Then Bizuwa and Sumnima attract Somdatta to the world of desires, passions and wordly life from his reclusive asceticism. With Bizuwa's suggestion, Sumnima takes Somdatta for a bath in a pond. Both of them take dips nude and then Sumnima cleans Somdatta's body and decorates and puts on him tribal Bhilla dress and rouses erotic desires in him. At dusk she leaves Somdatta on the banks of Koshi under the Sami tree and gives him a passionate erotic hug and a kiss and sends him to his house. She then heads towards her own home. With the romantic erotic impulse, Somdatta heads home whispering Sumnima's name and embraces Puloma. At that time Puloma was lost in the remembrance of a Bhilla boy. The erotic passion supplied by the memory of Sumnima and Bhilla boy's erotic self both of them had sexual intercourse to the heart's content. Then Puloma and Somdatta have a son and Sumnima on the other side had already given birth to a daughter.

After the birth of son, the tension grows in between Somdatta and Puloma's conjugal life. The son grows up amidst the tension of his parents. He happens to meet Sumnima's daughter on the Koshi bank where Somdatta and Sumnima in their childhood used to meet each other. Both of them are growing together and they usually meet at the Koshi bank. In course of time Puloma falls sick and dies. As the time proceeds, Somdatta also falls sick and dies on the lap of Sumnima. His orphan son lives with Sumnima. Somdatta's son passes his time with Sumnima's daughter and their friendship later culminates into marriage. Sumnima at the time of her death instructs her daughter to lead her life amicably with Somdatta's son:

And she addressed her daughter \& said, 'Daughter! the man who you have selected as your bridegroom is the son of a Brahmin. His blood is different. His mind is taken by some unknown things. They are the creatures of airtrying to move about in the air. They are never satisfied with the fullness of this life.... You are the daughter of a Kirat. We Kirats are creatures of soil, we love the soil. We are fully absorbed in the enjoyment of the pleasures of life, we don't see its lack. For us our body alone is the most loving thing. We regard the Brahmins like the kites with broken strings and they may think us like the earthworms.' (Koirala, 2005, p. 114) 
Sumnima dies suggesting the way of compromise to her daughter and the son-in-law for better conjugal life. The novel ends with her death.

Since the publication of the novel, it has been examined from numerous perspectives. Though it is approached through feminist, socio-political, linguistic, gender and psychological prospective, it has not been discussed from the point of view of humanism. The text remained unexplored yet from the humanistic prospective. Thus, this article aims to interpret it from the prospective of humanism.

Narayan Chalise (2012) in his book Purbeeye Darsanik Manyatama Koiralaka Upanyas, says that Koirala's Sumnima is a vivid picture of eastern philosophy ( $\mathrm{p}$. 127). He claims humanism as a prominent part of eastern philosophy. Analyzing the characters, he says Sumnima is a mouthpiece of the novelist to speak his concept of humanism (p. 127). He categorizes Sumnima and Bijuwa in the pole of humanism and Somdatta and Puloma in the next pole of religious rigidity. In the novel, the first pole triumphs the second one.

Koirala makes the binaries between Aryan and Kiranti culture in the novel. Somdatta represents Aryan culture whereas Sumnima represents Kiranti. The novelist has presented the Aryan ways of life in a complicated, artificial and formal way. To give lively presentation of Aryans life, he has depicted characters like Somdatta, his father Suryadatta, his mother, his wife Puloma, his son, and Puloma's parents. Among them, Somdatta is the representative character of Aryan society. In this novel the novelist has shown Kiranti community as liberal, purified, natural and follower of the humanitarian concept. Sumnima, her father, mother, the Bhilla boy in memory and Sumnima's daughter are the Kiranti characters. They approved the bodily aspect of life and their feelings are concerned with human pains and sufferings. They find truth in physicality, objective reality, bodily existence and the world of perception. (Dhakal, 2006, p. 33)

The continuous conflict between these two contradictory ideals of two cultures brings the theme of the novel. The novelist presents his mediatory view that religious orthodoxy fragments people and obstructs to reach the state of humanism. Humanism and humanitarian society is only possible in cultural reconciliation. Bhupati Dhakal (1999) in his book Bishweshwar Prasad Koiralaka Upanyasma Bichar Pakshye presents the conclusion as presenting the characters like Somdatta and Sumnima belonging Aryan and Kiranti culture stands for the spiritualism and materialism respectively (p. 68). The reconciliation between them shows his view of humanism.

\section{WHAT IS HUMANITY?}

All humanists have created an attitude of indifference towards religion. Every humanist examines the role of religion according to their own philosophical outlook. The humanists like Marx, Sartre, Feuerbach, and Russell dislike religion because it has not benefitted mankind. Russell goes beyond even Marx and Engels, who declared religion to the opium of the people. Humanist thinkers believe that humanist religion is nothing if it does not create right relations among people.

The primary aspect of religion which is fulfilling its proper role in human life is piety. Piety is not so important, but it is elementary as the constituting foundation of every religion. A reverent attitude towards parents, country, and the whole vast cosmos, out of which a person has emerged, becomes necessary for social relations.

Koirala's concept of religion is also human-centered because he opines that 


\section{Crossing the Border: International Journal of Interdisciplinary Studies}

human beings themselves are God whose spirit should express the eternal creativity through mankind. God is not apart from human and the individual is the replicate of this spirit. Human being represents the creator and they are the universal model of God, so that they convey the message that the real service of human being is the real service of God. An individual should adopt the religious beliefs through his/her creative services. Their services should not be limited within the religious orthodox as Jatava (1998) claims, "Socrates conceived man to exist as whole, unified, harmonious human beings" (p. 3). Socrates' thoughts are based on the concept of humanism because he develops humanistic tradition by revolting against any kind of hypocrisy and orthodox. He proves himself a unique example of the defender of universal humanism by emphasizing the need of self-knowledge by rejecting any kind of orthodox which is not based on human rational power.

Similarly, Buddha also presents the universal aspects of humanism. He denies the Hindu orthodox as Jatava (1998) says: "The Buddha revolted against all blind traditions and cruel orthodox of Brahmanism, which mutilated the beauty and grace of human existence" (p. 4). Buddha refuses the transcendent concept of Hindu and suggests that people are responsible members of society and they are a citizen with an interest of their own and the common welfare.

Hinduism is the major religion of Nepal followed by more than eighty percent of the population. In contrast to other religions, it has no founder. It has got its two sets; orthodox Hinduism and reformed Hinduism. Orthodox is the state of being orthodox which believes or opines on the traditional, dogmatic and firm sets of practices led by the Hindu religion. It has got its link to the earlier civilization on the Indian sub-continent, the Vedic age, the so-called "Aryan" culture which has developed its distinctive social institutions and theories. These theories are based on the concept of reincarnation, in which all living beings from plants on earth to gods above, are caught in a cosmic cycle of becoming and perishing. Russell comments these concepts of religious orthodox by saying that they are untrue and harmful because they are not based on scientific beliefs:

Russell is deeply concerned with man's place in the universe and the nature of the god. He does not find a true explanation of man's place in the universe in the existing religions like Hinduism, Islam, and Christianity, because to him they are both "untrue and harmful". No man is religious by reason and conviction. The religion which a man accepts is that of the community in which he lives. The influence of environment in is what leads a man to accept a particular religion. "I am that they are untrue", untrue, because they do not have scientific basis; harmful, because cruelties and crimes are committed in the name of religious sanctity. (as cited in Jatava, 1998, p. 23)

Russell says that dogmatic beliefs are the outcome of the religions that practice cruelty upon all sorts of people in the name of religion which has no rational and scientific basis. Religion is primarily and mainly grounded in fear. Fear is the basis of the whole thing- fear of mysterious, fear of defeat. A good society needs knowledge, kindness and courage; it does not need a regretful hankering after the religious orthodox or a faltering of the free intelligence by the words altered long ago by ignorant people. A good society needs a fearless outlook and a free intelligence that needs hope for the future, not looking back all the time towards religious orthodox that is dead, which people trust will be far surpassed by the future that our rational power can create. 
The Hindu Orthodox is the hurdle on the way of human being's free activities. Moreover, any kind of orthodox prevents the people from having a rational education. Orthodox prevents people from removing the fundamental causes of war. It prevents people from teaching the ethics of scientific, cooperation in place of the fierce doctrines of sin and punishment. People lack the harmony between moral quest and the scientific knowledge. All human being of the universe should get themselves united in the case of promoting the social conditions on which a more joyous and more widely shared human happiness depends. Orthodox denies human being for achieving a good society:

For the good and well-being of society, there is a need of 'social mutualistic cooperation. Extension of love and sympathy is also necessary for human welfare. People should not be blind to the sorrows and sufferings of the neighbors. And to perpetuate social tyranny, mass ignorance and untouchability, in his view, is to lose moral claims to be superior and humane. (Jatava, 1998, p. 108)

Koirala denies the religious orthodox but he believes in the spiritual connection of human being which unites the diverse experiences of a person in the vast universe. These experiences of a person hold that all have mutual duties and all sections of society are equal in respect and dignity. This system is a dull spiritless system that breeds conservatism and reactionary force.

Human beings are bound to certain religious beliefs; they can however, attend freedom and spontaneity in the spiritual world. The concept of humanism explored by Koirala rejects the narrow type of religious and cultural orthodox because his thought stands firm for the spiritual fellowship of all human being and conceives the coming era of the great federation and fellowship of all human being. Love, moral freedom and spiritual harmony are the underlying elements of spiritual unity. Through this unity, the humanism with universal values can be achieved in order to establish the world fellowship. The same idea is the central theme of the Koirala's Sumnima, which can be claimed, is written for the sake of humanity.

\section{SURPASSING CASTE AND CULTURAL BARRIER}

Koirala's Sumnima is based on cultural aspect of life. Kiranti and Aryan culture is put forth as a subject matter. To introduce these cultures is not an aim of Koirala rather producing thoughts is the primary aim through dialect between these cultural beliefs. Through the medium of Kiranti and Aryan culture, the novelist has presented his idea of materialism (body) and spiritualism (soul). Basically, the novel shows the dialect between spiritualism and materialism in which material aspect gets slight sympathy of the novelist. It is because, in a dialect, Sumnima, a representative character of materialism gives forceful logics to protest her beliefs. But in reality the spiritual ideology is also truly defended. As a whole, in the novel, both soul and bodily aspect of life are seriously presented. Not only that, it is shown in the novel that, both the aspect of life are incomplete within itself, rather they should have negotiation in order to become complete. The focus on negotiation makes the novel weighty and clarifies Koirala's idea of humanism at the same time.

Koirala's novel has chosen the characters from two different backgrounds. On the one hand, some characters are from Aryan culture and on the other hand others are from Kiranti culture. Among them, the main characters are Somdatta and Sumnima 


\section{Crossing the Border: International Journal of Interdisciplinary Studies}

because the novel has centered on the attitude of the characters towards life from which it has begun and ended. The novelist has demonstrated his view towards spiritual and physical aspects of life through them. He has expressed the humanistic attitude, attitude of sex, and love clearly. There are other characters too, but their role in the novel is just to fulfill the main characters' desire. The novelist has given lively presentation and vivid insights of all possible aspects of social realities through these characters from two different communities i.e., Aryan community and Kiranti community.

The novelist has presented the Aryan ways of life in a complicated, artificial and formal way. To give lively presentation of Aryans life, he has depicted characters like Somdatta, his father Suryadatta, his mother, Puloma, Puloma's parents and Somdatta's son. Among them Somdatta is the representative character of Aryan society.

Somdatta adopts an orthodox Aryan life style. His expression is the expression of Aryans which they made use by counting beads, spiritual rhymes. He is the last representative of Aryans, who has expressed the views of Aryans. His every word, every sentence and every ides are artificial. He is a blind believer of Aryan culture and leads on in ascetic way of life. He seems to have perceived the body, the passions, and the desires of a person merely as hindrances. He regards them as sinful representation which is unsuitable for an Aryan. He has distinguished the difference between Aryans and Kirants, and regarded Aryan lifestyle superior among others: "We are descendants of the Aryans, we are well cultured. You are wild Kirants, a community devoid of any good culture. Therefore, our concepts are different from yours" (Koirala, 2005, p. 7). This shows the arrogance of Somdatta being Aryan. He valorizes his culture and vomits his hatred over Kiranti culture at the same time.

His aspiration in life is to achieve, spiritual bliss beyond and above the real bodily pleasure. His aim seems to be imaginary, unearthly and ethereal salvation from the bondage of the body. The following lines show his idea clearly:

Religion is an entity of the endeavour while trying to rise above nature or

behaviour. The thing you call an attempt devoid of nature is nothing but a symptom rising higher than nature. Man cannot remain limited to behaviour and nature. He wants to move freely in the sky being free from this worldly bondage. (Koirala, 2005, p. 32)

He seems to have embraced the ascetic way of life. In the conversation with Sumnima before his marriage to Puloma and even after the marriage to Puloma, he has shown himself responsible towards Aryan religion and culture. He got married to a woman according to his father's choice just to continue his lineage not to fulfil his passion or gaining erotic fulfillment:

With a complete lack of interest and in a voice of extreme detachment

Somdatta asked his mother, 'Mother! What is the purpose of marriage for me?'

Father answered to this, 'Son, marriage is for bearing children and it is thus an act of religious rite.

Somdatta said, 'But I have thought to remain a bachelor all my life.'

'Dear Son! A marriage performed to fulfill some duty is not only blameless

but inspired by religion too.' (Koirala, 2005, p. 40)

Somdatta gets married for the sake of religion not for the need of livelihood. But, the novelist does not approve the life style of Aryans. He sees snobbery, tyrannical attitude and self sufferings. So he rejects this kind of life style. He made satire on 
Aryan life style by making Somdatta and his wife, Puloma incapable of reproduction though they perform hard penance with a severe neglect of physical care. The lifeless and fruitless monthly ritual of reproduction devoid of physical pleasure makes the Aryan couple a laughing stock in the eyes of the readers. Thus, he has presented Aryan lifestyle as unnatural, inhuman and corrupt one.

In the novel, Koirala has shown Kiranti community as liberal, purified and natural. They give more priority to self, physicality, emotion, desire, and bodily pleasure. Sumnima, father-Bizuwa, her mother, the Bhilla boy (in memory) and Sumnima's daughter beong to that community, among them Sumnima is a representative character. The Kiranti characters have approved the bodily aspects of life and their feelings are concerned with human pains and sufferings. They find truth in physicality, objective reality, bodily existence and the world of perception.

Sumnima's attitude is natural and she loves physicality rather than spirituality. She loves body in a natural way. Her view about life is different from Somdatta's view about life:

Sumnima abandoned her laziness and said, 'Look, look Somdatta! What a pretty pigeon! Its legs are red and the eyes are red too.'

Before Somdatta's eyes feel on the pigeon as if emerging from the void of the sky a falcon came down at a tremendous speed upon the pigeon which had not been able to settle itself well on the Shami branch. But the concentration of the falcon was broken terror-stricken and fell down from the tree close to them. The falcon flew away. Somdatta picked up the pigeon and began toe caress it with affection. Sumnima said, 'What a pretty white pigeon, right? How lovely its legs, so soft and tender.' (Koirala, 2005, p. 20)

The given lines show Sumnima's innocence. She is attracted with beauty of pigeon but unaware of the crisis it faced recently. She takes natural rules easily and suggests Somdatta also to take easily. But Somdatta is of different kind:

The attention of Somdatta was not at the pigeon's beauty. He said, 'Ah! Its life was protected.'

The idleness which Sumnima felt just a moment ago was now gone completely. Her body felt a kind of vigour when she saw Somdatta caressing the pigeon that way. She eyed at Somdatta obliquely and with a playful agility said, 'But alas! The poor hawk couldn't save its life!' (Koirala, 2005, p. 20) Somdatta, who supposes Sumnima as an uneducated and ignorant, gets great shock. He takes even smaller things as a great matter. He feels pity on a pigeon and relaxes saving the life of the pigeon but seems unaware to the system of the nature. Hawak is by nature given rights to kill. Without killing, it cannot save its life. If there is right of life to the pigeon, the equal right is given to the hawak by nature. Sumnima satires on Somdatta's idealistic concept and suggests him to follow natural laws as human beings are also the creation and the part of nature.

In comparison to Somdatta, Sumnima is very free to think, to understand and to experience. She loves nature, natural world and thinks of physicality as a better religion in the world. She does not like the imaginative world of Somdatta. She held the notion that being human one must talk about human. She sees truth on the phenomenal existence but Somdatta regards it as different: "There are five uncontrollable horses of sense organs which are indisciplined, uncultured, unsuppressable and savage. The aim of spiritual practice is to bring them under your 


\section{Crossing the Border: International Journal of Interdisciplinary Studies}

control like a skilled horse rider does" (Koriala, 2005, p. 29). Somdatta borrows these lines from Vedic books and speaks to Sumnima to show his knowledge and keep supremacy over her. But he seems bookish and becomes unable to convince her. $\mathrm{He}$ seems impractical.

Koirala demonstrates his humanitarian view through Sumnima. As a social realist with modernist outlook, he focuses on objective reality that is related with human pains and passions. According to him, being a human being we should have faith in physicality and the world of perception rather than the spirit and the world of senses. He makes reader aware of the limitations and polarities of life. Thus, through Sumnima, he tries to show humanitarian view as

Somdatta answered patiently, 'This is the language of gods.'

'Then, why don't you speak in a human language being a human yourself? In my view being human beings we should not follow god's behavior. Somdatta, we should practice human customs as we are human beings.' (Koirala, 2005, p. 8) Sumnima seems to be practical. She emphasizes to become human being and act like that. She says being human is real and the concept of God is ideal, which has no ground in physical world. So, being human, one should speak human language and trying to copy the language of God is unnatural. She further states,

It is the human who lives within a human being according to my father. Deities live in their respective places, some live on tops of mountains, some in the rivers, some in the rocky cliffs, some in the jungles and others in the agricultural fields. Within us lives a human spirit, not anybody else. Father warns that these two are not the same; they should not be mixed up. They have their separate identities; they live separately and differently and work independently of each other. (Koirala, 2005, p. 19)

Sumnima tries to differentiate between God and human being. The concept of God is illusory and unclear. It is only an idea. But human is real. She suggests Somdatta to be the realist and not to destroy the arrangement of nature by bringing incongruous arguments from religion uselessly. She believes that to destroy the structure of nature is to destroy own self.

Koirala presents the dialects of right and wrong, perishable and permanent, through the dialogues between Sumnima and Somdatta. Somdatta's blind faith in the spirit, his ideological notion, his objective phenomenal existence and the world of senses becomes valueless before the faith of Sumnima on body, on physicality, objective reality and the world of perception:

You people put clothes on anything and cover their real identity. You hang a mask on the face of an undamaged person with recitation of sacred words, penance and rituals of fire sacrifice and fasting and cover the body with all kinds of garments and dresses and talk about it the same manner of incomprehensible speech. (Koirala, 2005, p. 9)

In the above lines, Sumnima disagrees with Somdatta's unnecessary formalities. She says formality covers originality and makes human identity mystical. She further criticizes:

I only said this much that numerous kinds of things that crop in the mind, which you perhaps call 'sentiment', and I pray, don't make it incompatible and unsuitable to the soil of the earth where we live. Sentiment is like a bird with wings. That bird flies freely and aimlessly in the vast expanse with no beginning and end of the void of this huge sky. It can reach as high as it wishes. 
Our relation, however, should be with the earth. We are human beings and as humans we must be tied to the customs of humans. (Koirala, 2005, p. 10) Sumnima tries to convince Somdatta to come on the real ground. Human beings are the creature of earth, wandering on airy things may mislead human life and make the life vain. Being human, one should keep relation to earth where lays the real existence of human beings.

Being human one should not be far away from responsibilities towards human religion. Human religion can be achieved with simple and natural way and it can achieve love from body and physicality. Love for tangible human life permeates all over the novel through Sumnima, her father and her daughter. That's why Koirala made Sumnima win the conversation with Somdatta and made him go to Kirant village in search of a house of Bizuwa, the father of Sumnima. The novelist wants to express his humanitarian view by Kiranti characters. First he has expressed humanitarian view through Sumnima and to help her view, he makes Bizuwa as mouthpiece and heightens the Kiranti culture. By doing rigorous penance, self-sacrifice and rituals, Somdatta has moved away from human-religion and humanitarian concept. But his effort to gain spiritual refinement fail to give birth to son finally as monotonus rituals wants to lead life a simple and natural life as the Kirantis live. Here, the novelist expresses his humanitarian view through Bizuwa:

The Bijuwa asked him in the voice of his professional novelistity, like a physician to his patent, 'Why do you need a son?'

Somdatta said, 'Our ancestors would not be salvaged if we do not have issues for protecting our religion. Without children all the religious piety earned in this mortal world will be useless. That is what our religious scriptures prescribe.' (Koirala, 2005, p. 44)

Bizuwa wants to solve the problem of Somdatta. But he is amazed when he knows Somdatta's purpose of having baby. He understands that Somdatta has gone too far from physical world and only floating at the world of idealism as it is mentioned in the novel:

The Bijuwa asked again. 'And besides that?'

'We do not harbour any other purpose for getting a son except it.'

'Didn't you even feel that while you were engaged in a sexual union with a woman that your body was enjoying?'

'Not a bit!'

'Then do you desire a son just for keeping the religious tradition? And not for the pleasure of your body at all?'

Somdatta replied firmly, 'Not Between pleasure and duty we have killed the desire for pleasure with penance. In our life our objective is only fulfilling the duty'. (Koirala, 2005, p. 55)

This shows the pompousness of Somdatta that he needs a child to clear his ways for heaven and to get privileges there in future. But he is negating the present. He aims to get comfort in heaven but rejects worldly pleasure. Bizuwa's questions are related with human-religion, physicality, wordlyness and present time. Thus, to attract Somdatta towards worldliness, the novelist has made Bizuwa medium; and he expresses,

The Bizuwa remarked very seriously, 'O Brahmin! The man in you is angry with you because you tried to kill it with penance. You must take a dip into the man's pond. . . . . 'Our body is not a machine, nor a medium, nor a means. 


\section{Crossing the Border: International Journal of Interdisciplinary Studies}

It is itself a goal, an objective. You shouldn't neglect and hate it. When the physical body of man is devoid of its juice, the desire of pleasure and feeling of enjoyment, it is like lifeless; and it cannot bear children. The body is not a lifeless emotionless tool only. A baby is the result and proof of copulation, do you understand O Brahmin?' (Koirala, 2005, p. 56)

Bizuwa tries to drag the attention of Somdatta from idealistic world to the physical world. He presents the importance of physicality. He knows that Somdatta has ignored his body and its desire in order to make his penance successful. Because of his ignorance to body, he is unable to give birth to the child. Somdatta seems to be known of many things of human life and the life after death. But he is still seems unaware that to give birth to the child, physicality is more important than idealism, which he knows only after Bizuwa taught him.

The Bizuwa said, 'Sumnima! Brahmin Somdatta's man within him has gone angry because he hated his own man. Yes Somdatta, it's true that if the inner man is hurt he is angry. His habit is like that of a child. Ok Sumnima! We must now please his man within him.' (Koirala, 2005, p. 57)

In the above citation the novelist through Bizuwa has talked about humanitarian view and regarded bodily aspects of life as being better.

Similarly, Sumnima’s daughter represents Sumnima’s concept of passion, spirits and her faith on objective reality. When Somdatta's son calls air beautiful, Sumnima's daughter shatters his faith in abstraction and states:

Somdtatta's son said in an affectionate tone. 'Yawa, look! How pleasant it is!

Sumnima's daughter asked, 'What is pleasant, Yawa?'

Somdatta's son said, 'The air!'

Sumnima's daughter laughed in a big guffaw, She said, 'Is the air pleasant at all anywhere, Yawa? For me it's you who is pleasant. We cannot touch air, as far as you are concerned, look, I can touch you too'. (Koirala, 2005, p. 111)

Thus, the novelist has approved the life style of Kiranti. And we find Sumnima, Kiranti who possesses the qualities of an Aryan and Somdatta, the Aryan but having the quality of Kiranti. The novelist has explored the culture of Kiranti and Aryan by applying the theory of comparison and contrast. He is successful to convince the reader that Kiranti culture is superior between two.

Sumnima defeated Somdatta's ideological notion, and became an acting force for the birth of his son: "This my son is sprouted in the mental womb of Sumnima" (Koirala 103). She takes Somdatta in the pond where she creates a romantic desire on his mind and makes a failure of his reclusive asceticism. Somdatta attends erotic pleasure with his wife, Puloma only when Sumnima is in his memory. Puloma becomes pregnant, which his yagnas has failed to do so and his strong inclination and understanding of dharma has failed to show. These events reveal that Sumnima has victory over Somdatta's faith.

In the beginning of the story, the novelist makes Sumnima to advocate about the bodily lifestyle and Somdatta to sing the value of ascetic way of life. From their dialogue the novelist presents the major ideology, characteristics and the theme of both cultures. In the main time, the novelist introduces the prince who gives order to the Kirat and Bhilla not to offer animal sacrifice in the name of god surrounding Somdatta's Aashrama. From this point the dialect gets new turn to negotiation. The Bhilla boy incites kirant to fight to save their right but the head of Kirant, Bijuwa 
argues for negotiation:

The Bijuwa explained it further, "Bhilla youth! You are rather talking like the Aryans who always boast of getting religious salvation and freedom from sins after death. It may be meaningful if we accepted the advice of war for living, but it is never acceptable to wage war for earning piety after sacrificing life. The Aryans fought a great war in the name of religion called the Mahabharat. What did they achieve except the mountains of dead bodies? No, I don't subscribe to your suggestion of war. Everyone will benefit by living together in friendship and peace. (Koirala, 2005, p. 16)

These lines explain the vanity of war and the novelist raises the question over the rationale of the war of Mahabharat. He suggests people to fight for humanity and human existence. If there is only loss of human existence and humanity, what is the use of fighting? Rather it is better to stretch the arms of friendship for negotiation and save human being and humanity.

The novelist at the middle of the story makes silence to the follower of the bodily aspect of life and gives chance to evaluate the strength and limitation of the follower of spiritualism. Somdatta, getting victory over body and sense organs returns to the hermitage and has to encounter a religious complication. He has to get married and give birth to the child in order to lead his ancestors easily to salvation. The act of marrying Puloma to continue lineage only seems pompous. Furthermore, the ceremony they perform to give birth to the child is ridiculous. They are detached from sensation and bodily pleasure but keeping physical relation to get child in the name of holy act, makes reader laugh and shows the uselessness of religion and spiritualism. Following spiritual way ardently, they perform the norms and values written in the religious books in order to get a child. But the timely menstruation of Puloma every month shatters their dreams which makes them frustrated and suspect each other if they have done some unreligious deeds.

Somdatta was sad and thought in his mind, 'Had Puloma in anyway got some curse...?'

Puloma also got tired in body and mind and began to think, 'This Brahmin must have committed some sin in his former life and the god of fate hasn't written on his forehead getting a son'. (Koirala, 2005, p. 49)

The suspicion of them to each other shows their religious dogmatism. They are still thinking that they had done religious mistake but are not aware of their physical mistake that they have committed.

Creating such a situation, the novelist incites Somdatta to visit the head of the Kirant with the hope of suggestions. This boosts the ideal of the novelist that negotiation can be the solution of each problem. Bijuwa, the head of Kirant gives him suggestions and also orders Sumnima to take him to the man's pond and give him bath in order to evoke his manly desire which he had killed through penance. This selfless help of Bijuwa clarifies the ideal of humanism that only human being could help others in their suffering and pains. Sumnima also helps him from her heart forgetting all the mistreatment he had done to her. In this way, Somdatta who always hated Kiranti culture and supposed the "ditch of sins" became the solution of his problems. This shows how Somdatta and his belief on spiritualism are empty in itself.

Somdatta is not defeated by Sumnima but also by his wife, Puloma. Puloma, though she seems a submissive character in front of Somdatta later becomes 


\section{Crossing the Border: International Journal of Interdisciplinary Studies}

rebellious female character. Somdatta's superiority, his rationality, his virility has no value in front of her. After the birth of Somdatta's son they cannot retain homely relation in the latter half of their career and they do not have any sense of affection. His own son, his own blood becomes stranger to him. Puloma distances his son through him calling him: "A fatherless unfortunate boy!" (Koirala, 2005, p. 103). It shows that Somdatta is nowhere in the life of his wife and his son.

The novelist does not show the defeated position of Somdatta and his belief only but also Sumnima and her belief too hinders at last. Sumnima, the ardent supporter of physicality also gets change and thinks that dreams, feelings, ideals and soul are as important as physicality in life. The following lines of Sumnima show her acceptance of spirituality: "I spent my life in a great distress for many years after you avoid me. I felt that there was no charm in anything as I thought everything was bland and tasteless" (Koirala, 2005, p. 69). Even after her marriage she cannot satisfy her husband:

My husband says to me that he didn't get me.... The whole night I sleep stuck to his body and even then he says that he didn't get me. We have a daughter; even then he says he didn't have me. He says that he will now go to Kashi and there he will adopt a lineage like that of a Brahmin and will also embrace a big dream. (Koirala, 2005, p. 69)

This is quite enough to know that Sumnima cannot forget Somdatta even after her marriage. She gets physical love and care but still lacks something in her life that is her childhood love: "Even a wounded tree grows if the sap needed for its survival is present within it and it got situation to thrive. And besides, my husband is like you. When I spend my night with him I feel that I am with you. If you have to live you do have to embrace dreams like that, haven't you?" (Koirala, 2005, P. 69). Sumnima realizes the incompleteness of bodily aspects of life. She cannot forget her childhood love and realizes that to have better life, dreams and ideal also be embraced by human beings.

Towards the end of the novel, Sumnima's attitude towards life changes into middle path. She realizes the negotiation is must in life. The body and soul is needed for better life. She herself has a clear attitude of life. She realizes that the incompleteness in bodily aspects of life where spiritual aspects of life is unknown to her. She explaines, "We regard the Brahmins like the kites with broken strings and they may think us like earthworms" (Koirala, 2005, p. 114). Realizing the importance of body and soul for the fulfillment of life she instructs her daughter and Somdatta's son to lead a good life.

In the course of time Somdatta also realizes his defeated position in front of Sumnima and he has no desire to live:

In truth, Somdatta had no desire to live. He felt that his whole life was a failure; he realized that all his life he ran after an illusion. All the counting of beads with sacred words, recitation, worship, penance and his efforts for salvation went in vain. Even the getting of son was useless. The relation with his son was not of any affection or closeness at all. Somdatta, who was lying on the bed counting the hours of his death, thought, 'Where are all the achievements, any achievement?' And while thinking he was desperate and breathe a heavy sign. (Koirala, 2005, p. 107)

Sumnima's place is heightened by Koirala making Somdatta die in the lap of Sumnima whispering her name. After his death Somdatta's son lives with Sumnima and he does not keep anything that reminds him of his father: "The son had no any 
kind of feeling of love towards his father. Therefore, he didn't see the need of keeping anything for the memory of his father. All those things of his dead father were of no need at all for him. He said, "No, I don't want to keep them!" (Koirala, 2005, p. 109). This shows that along with Somdatta, his beliefs and the ways of life he lived is in transition. His own son does not follow his ways and gets mingled with Kiranti culture. It gives the sign of new midway culture.

At last, Sumnima allowed the intercaste marriage to her daughter with Somdatta's son that was not permitted and acceptable. She instructs her daughter and Somdatta to lead her life amicably with Somdatta's son and blesses them: "May you prosper! May your descendants be such to be able to find out the ways of compromise!" (Koirala, 2005 , p. 114). This final lines of Sumnima speak the theme of the novel that human beings are fragmented in the name of caste, culture, religion and many others. These fragmentations make people unhappy and their life becomes vain. But negotiation, compromise and better understanding between them makes life meaningful. Unity among the diversity is the way to flourish the culture of humanism.

\section{CROSSING THE BORDER}

Hinduism is the major religion of Nepal followed by the more than eighty percent of the population. In contrast to other religions, it has no founder. It has got its two sets: orthodox Hinduism and reformed Hinduism. Orthodox is the state of being orthodox which believes or opines on the traditional, dogmatic and firm sets of practices led by the Hindu religion. It has got its link to the earlier civilization on the Indian sub-continent, the Vedic age, the so-called "Aryan" culture which has developed its distinctive social institutions and theories. These theories are based on the concept of reincarnation, in which all living beings from plants on earth to gods above, are caught in a cosmic cycle of becoming and perishing.

Dogmatic beliefs are the outcome of the religion that practice cruelty upon all sorts of people in the name of religion and culture which has no rational and scientific basis. Religion is primarily and mainly grounded in fear. Fear is the basis of the whole thing - fear of mysterious, fear of defeat. A good society needs knowledge, kindness and courage; it does not need a regretful hankering after the religious and cultural orthodox or a faltering of the free intelligence by the words altered long ago by ignorant person. A good society needs a fearless outlook and a free intelligence that needs hope for the future, not looking back all the time towards religious and cultural orthodox that is dead, which people trust will be far surpassed by the future that their rational power can create.

An orthodox religion and culture is the hurdle on the way of man's free activities. Moreover, any kind of orthodox prevents the people from having a rational education. Orthodox prevents people from removing the fundamental causes of war. It prevents people from teaching the ethics of scientific, cooperation in place of the fierce doctrines of sin and punishment. Due to the orthodox, one lacks the harmony between moral quest and the scientific knowledge. All human beings of the universe should get themselves united in the case of promoting the social conditions on which a more joyous and more widely shared human happiness depends. Orthodox denies human being for achieving a good society.

Koirala denies the cultural religious orthodox but they believe in the spiritual connection of human beings that unites the diverse experiences of them in the vast 


\section{Crossing the Border: International Journal of Interdisciplinary Studies}

universe. These experiences hold that all have mutual duties and all sections of society are equal in respect and dignity. They condemn the caste basis of the society. This system is a dull spiritless system that breeds conservatism and reactionary force.

\section{CONCLUSION}

Human being is bound to certain religious beliefs; they can, however, attend freedom and spontaneity in the spiritual world. The concept of humanism explored by Koirala through his novel rejects the narrow type of religious and cultural orthodox because their thought stands firm for the spiritual fellowship of all human being and conceives the coming era of the great federation and fellowship of all people. Love, moral freedom and spiritual harmony are the underlying elements of spiritual unity. Through this unity, humanism with universal values can be achieved in order to establish the world fellowship. The same idea that crossing all the borders created by caste, culture and religion is carried by the novel Sumnima which can be claimed is written for the sake of humanity.

\section{REFERENCES}

Chalise, N. (2012). Purbeeya darsanik manyatama Koiralaka upanyas. Dang: B.P Chintan Kendra.

Dhakal, A. (2006). Treatment of female characters in Bishweshwar Prasad Koirala's Sumnima. Diss. Tribhuvan University.

Dhakal, B. (1999). Bishweshwer Prasad Koiralaka upanyasma bichar pakshya. Pokhara: Jaynepal Prakashan.

Jatava, D.R. (1998). Social and humanist thinkers: Indian and western. Jaipur: Ina Shree.

Koirala, B.P. (2005). Sumnima. Trans. Tara Nath Sharma. Kathmandu: Bagar Foundation.

\section{ABOUT THE AUTHOR}

Min Nepali has received his master's degree from the Department of English, Tribhuvan University, Prithvi Narayan Campus, Pokhara. His paper is built upon his master's thesis entitled "Transcending Cultural and Religious Barriers in B.P. Koirala's Sumnima and Rabindranath Tagore's Gora: A Humanistic Study." Currently he teaches English at Kalika Public College, Ram Bazar, Pokhara.Email: napalimin78@gmail.com 